\title{
Gastric dysrhythmias occur in gastro-oesophageal reflux disease complicated by food regurgitation but not in uncomplicated reflux
}

\author{
A Leahy, K Besherdas, C Clayman, I Mason, O Epstein
}

\begin{abstract}
Aim-To investigate gastric pacemaker activity in gastro-oesophageal reflux disease using the electrogastrogram.

Patients-Forty patients with gastrooesophageal reflux disease ( 20 with acid reflux, 20 with the additional symptom of food regurgitation) and 30 asymptomatic controls.

Methods-Patients were studied using an electrogastrogram, oesophageal manometry, and 24 hour ambulatory oesophageal pH analysis.

Results-An abnormal electrogastrogram was recorded in two $(7 \%)$ controls, two $(10 \%)$ patients with acid reflux, and 10 $(50 \%)$ patients with food regurgitation. Food regurgitators had significantly more gastric dysrhythmias (tachygastrias) both before $(p<0.02)$ and after $(p<0.01)$ a test meal. Gastric pacemaker activity was also significantly less stable following the test meal in food regurgitators $(p<0.003)$. Patients with food regurgitation and an abnormal electrogastrogram had higher oesophageal acid exposure than those with a normal electrogastrogram $(p<0.05)$. Conclusions-The electrogastrogram is usually normal in gastro-oesophageal reflux disease but an abnormal rhythm occurred in half of our patients with the additional symptom of food regurgitation. Furthermore, an abnormal electrogastrogram is associated with increased oesophageal acid exposure.

(Gut 2001;48:212-215)
\end{abstract}

Keywords: gastro-oesophageal reflux; gastrointestinal motility; electrogastrogram

The electrogastrogram (EGG) is a noninvasive method of recording gastric myoelectrical activity. The activity is detected by positioning cutaneous electrodes over the upper abdomen and capturing the mean electrical frequency of the gastric pacemaker. Normal gastric myoelectrical activity consists of a slow wave and spike potentials. The EGG records the slow wave, which controls the velocity and propagation of gastric contractions. This oscillates within a narrow frequency band, and any gastric activity outside this band is designated a dysrhythmia.

Gastric dysrhythmias consist of fast frequency (tachygastrias) and slow frequency (bradygastrias) waves. Studies using serosal transducers and manometry have shown that tachygastrias correlate with absent antral contractions. ${ }^{12}$ Bradygastrias have been reported to associate with both strong or absent antral contractions. ${ }^{1-4}$

Reliability of the EGG has been well documented by comparing mucosal with serosal electrodes. ${ }^{15-7}$ Reproducibility has been demonstrated by the observation that the amount of normal activity does not significantly change if performed on separate days. ${ }^{8}$ Furthermore, the EGG is not significantly affected by age or sex. ${ }^{9}$

The pathogenesis of gastro-oesophageal reflux disease (GORD) is multifactorial..$^{10}$ Transient relaxation of the lower oesophageal sphincter and delayed oesophageal clearance are important but gastric factors have also been implicated. ${ }^{10}$ A number of studies have demonstrated delayed gastric emptying for solids or liquids in GORD but other studies have failed to demonstrate this correlation. ${ }^{11}$ The inconsistencies remain unexplained and the role of gastric motility in GORD requires further clarification. The EGG not only provides information on gastric myoelectrical activity but also predicts gastroparesis with an accuracy of $78 \% .^{12}$

Gastric dysrhythmias have been described in a variety of disorders including functional dyspepsia, motion sickness, nausea of pregnancy, anorexia nervosa, and idiopathic and diabetic gastroparesis. ${ }^{12-18}$ There is a report that the EGG may be abnormal in elderly patients with GORD. ${ }^{19}$

The aim of this study was to investigate gastric pacemaker activity in GORD. The study was designed to assess the EGG both in uncomplicated GORD and in a subgroup who, in addition to GORD, had an additional predominant symptom of food regurgitation. To evaluate and compare GORD patients with or without food regurgitation, the lower oesophageal sphincter and oesophageal acid exposure were also assessed.

\section{Methods}

Subjects prospectively studied included 40 patients with GORD and 30 asymptomatic controls. GORD patients were characterised by a clinical presentation of heartburn and/or acid waterbrash. In all GORD patients the diagnosis was confirmed by 24 hour oesophageal $\mathrm{pH}$ analysis and/or the finding of oesophagitis on oesophagogastroduodenoscopy. Within the

Abbreviations used in this paper: GORD, gastro-oesophageal reflux disease; EGG, electrogastrogram; FFT, fast Fourier transform. 
A

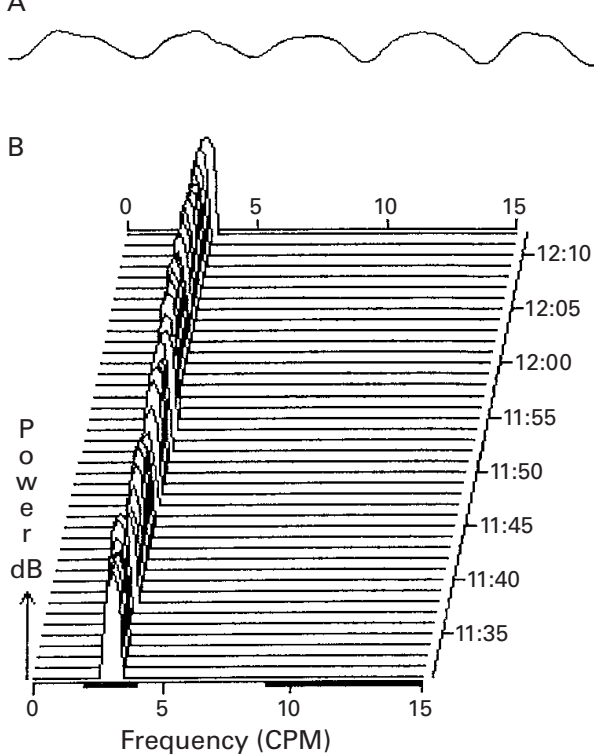

Figure 1 An example of $(A)$ an electrogastrogram (EGG) signal and (B) a pseudo three dimensional representation of its analysis in a control subject. Normal electrical activity of 2-4 cycles per minute is present after a test meal.

GORD group there were 20 patients with typical acid reflux symptoms and 20 patients with the additional symptom of food regurgitation. The regurgitation patients were characterised by a predominant complaint of involuntary solid or semisolid food regurgitation into the mouth. All patients had an oesophagogastroduodenoscopy performed. Patients with Barrett's oesophagus, oesophageal ulceration, stricture, or malignancy were excluded from the study. The control group consisted of healthy individuals who did not complain of gastrointestinal symptoms.

The EGG was performed following a six hour fast. Any medication with potential to influence gastric motility or acid production was discontinued for at least 48 hours before the motility recordings. Patients were studied in a semireclining position and requested to avoid major movements. The skin was lightly abraded with gauze prior to placement of the adhesive gel EGG electrodes. Two bipolar skin electrodes were placed on the abdomen; one midway between the xyphoid process and umbilicus, and the other $5 \mathrm{~cm}$ to the left, just below the costal margin. A reference electrode was placed on the right side of the abdomen. ${ }^{20}$ The electrodes were connected to an EGG recording unit (Synectics, Stockholm, Sweden). A one hour fasting recording was performed after which the patient drank 150 $\mathrm{ml}$ of water and ate a standardised cheese salad sandwich (575 kcal; 50\% carbohydrate, 25\% protein, $25 \%$ fat). This was immediately followed by a one hour postprandial recording.

A standard method for data analysis was performed. ${ }^{21}$ The EGG data were analysed by the "multigram" Synectics software package running on a personal computer. A sampling frequency of $4 \mathrm{~Hz}$ was used. The EGG analysis is based on the fast Fourier transform (FFT) technique. A data period of four minutes and
A

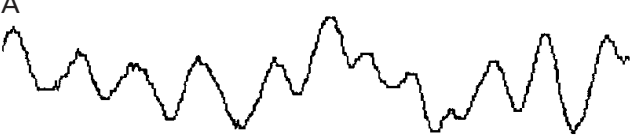

B

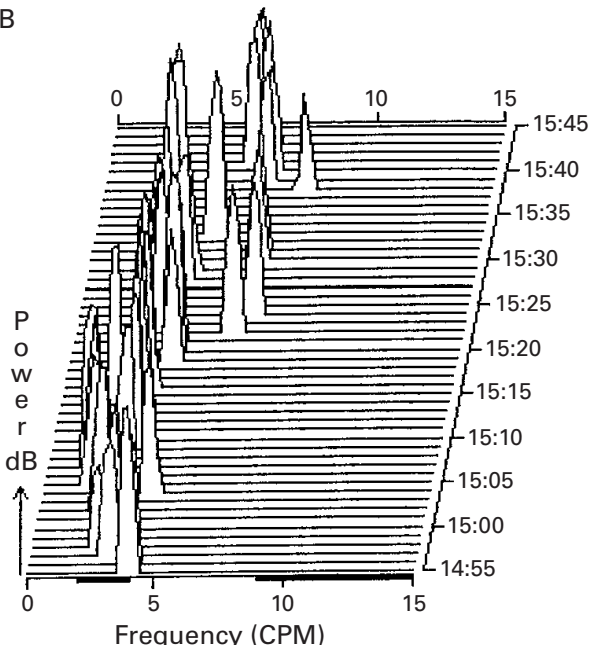

Figure 2 An example of $(A)$ an electrogastrogram (EGG) signal and (B) a pseudo three dimensional representation of its analysis in a patient with food regurgitation. An abnormal EGG is present, with gastric dysrhythmias occurring after a test meal.

16 seconds is analysed and termed an FFT line. The dominant frequency for each FFT line is calculated and consecutive data periods are displayed by running spectrum analysis. The FFT lines are displayed at one minute intervals, which corresponds to an overlap of three minutes and 16 seconds between data sets for adjacent FFT lines. For the periods before and following the test meal, an average FFT line is calculated, from which the power of the dominant frequency is derived. Prior to analysis of the EGG signal, visual inspection of the waveform detected any obvious major movement artefacts. These were defined as abnormally large positive and/or negative peaks in the tracing and were deleted from the analysis. Due to overlap of data displayed as FFT lines, a major movement artefact results in deletion of approximately five minutes of data.

Normal electrical activity was defined as a frequency of 2-4 cycles per minute. Activity of $0-2$ cycles per minute was termed bradygastria and 4-9 cycles per minute as tachygastria. An abnormal EGG was defined as $<70 \%$ normal electrical activity either before or after the test meal. ${ }^{13} 22$ The power (or amplitude) of the dominant frequency was measured both before and following the test meal, and the postprandial to preprandial power ratio was calculated. The stability of the EGG frequency before and after food was calculated, and expressed as a dominant frequency instability coefficient.

The lower oesophageal sphincter was assessed by standard oesophageal manometry performed following a six hour fast. A four channel water perfused system (Synectics, Stockholm, Sweden) was used with the patient positioned in the supine position. Mean end expiratory pressure and mean total and abdominal lengths of the lower oesophageal sphincter were recorded by a stationary pull 
Table 1 Median values (interquartile ranges) for the electrogastrogram in gastro-oesophageal reflux disease

\begin{tabular}{lccc}
\hline & $\begin{array}{l}\text { Controls } \\
(n=30)\end{array}$ & $\begin{array}{l}\text { Acid reflux } \\
(n=20)\end{array}$ & $\begin{array}{l}\text { Food regurgitation } \\
(n=20)\end{array}$ \\
\hline Preprandial & & & \\
$\quad$ Bradygastria & $2.2(0-8)$ & $3.7(0-8)$ & $4.7(1-9)$ \\
$\quad$ Normal & $86.8(76-98)$ & $89.6(84-97)$ & $82.1(75-90)$ \\
Tachygastria & $2.7(0-9)^{\star}$ & $5.0(0-9)$ & $11.2(5-16)^{\star}$ \\
DFIC & $23.0(13-34)$ & $23.0(9-31)$ & $33.5(21-39)$ \\
Postprandial & $2.0(0-4)$ & $2.1(0-6)$ & $5.9(0-10)$ \\
Bradygastria & $94.1(82-100)^{\star \star \star}$ & $88.0(76-96)$ & $73.6(66-93)^{\star \star \star}$ \\
$\quad$ Normal & $3.9(0-8)^{\star \star}$ & $5.6(0-17)$ & $15.0(4-22)^{\star \star}$ \\
Tachygastria & $17.0(9-27)^{\star \star \star}$ & $23.5(17-34)$ & $33.5(21-39)^{\star \star \star}$ \\
DFIC & $1.7(1-4)$ & $2.3(1-5)$ & $1.7(1-4)$ \\
Power ratio & & &
\end{tabular}

Values are percent of the recording except for power ratio. Regurgitation patients had significantly more tachygastrias throughout the whole recording, and a more unstable electrical frequency following the test meal.

DFIC, dominant frequency instability coefficient

${ }^{\star} \mathrm{p}<0.02 ;{ }^{\star \star} \mathrm{p}<0.01 ;{ }^{\star \star \star} \mathrm{p}<0.003$.

Table 2 Mean (SD) values for oesophageal manometry and 24 hour oesophageal $p H$ analysis in gastro-oesophageal reflux disease

\begin{tabular}{|c|c|c|c|}
\hline & \multicolumn{3}{|c|}{ Food regurgitation $(n=13)$} \\
\hline & $\begin{array}{l}\text { Acid reflux } \\
(n=20)\end{array}$ & EGG normal & EGG abnormal \\
\hline \multicolumn{4}{|l|}{ Lower oesophageal sphincter } \\
\hline Mean pressure $(\mathrm{mm} \mathrm{Hg})$ & $11.8(5.4)$ & $7.2(3.5)$ & $8.7(3.8)$ \\
\hline Mean total length $(\mathrm{cm})$ & $3.6(1.1)$ & $3.6(1.3)$ & $3.9(1.7)$ \\
\hline Mean abdominal length $(\mathrm{cm})$ & $2.0(1.0)$ & $2.2(0.8)$ & $2.2(1.0)$ \\
\hline \multicolumn{4}{|l|}{ Oesophageal acid exposure } \\
\hline $\begin{array}{l}\text { Mean Demeester score } \\
\quad(\text { normal }<14.72)\end{array}$ & $58.6(42)$ & $25.5(11)^{\star}$ & $93.5(78)^{\star}$ \\
\hline $\begin{array}{l}\text { Mean percentage } \mathrm{pH}<4 \\
\quad(\text { normal }<4.45)\end{array}$ & $14.0(10)$ & $6.3(4) \star$ & $23.2(18)^{\star}$ \\
\hline
\end{tabular}

Food regurgitators with an abnormal electrogastrogram (EGG) had significantly higher oesophageal acid exposure than those with a normal EGG $\left({ }^{\star} \mathrm{p}<0.05\right)$. There were no significant differences in lower oesophageal sphincter measurements between food regurgitation patients with a normal and abnormal EGG. gitation $8 / 12$. A Demeester score $>14.72$ was recorded in all acid reflux patients and in 13/20 food regurgitation patients. There were seven food regurgitation patients who did not undergo $\mathrm{pH}$ monitoring, and all had oesophagitis on oesophagogastroduodenoscopy. Oesophagogastroduodenoscopy showed no other significant mucosal disease except that two patients with acid reflux and 13 with food regurgitation had Savary-Miller grade 1-2 oesophagitis. No laryngeal or pharyngeal inflammation was seen in any patient.

An abnormal EGG was defined as $<70 \%$ normal electrical activity either before or after the test meal. ${ }^{13} 22$ Eight asymptomatic controls $(27 \%)$ demonstrated a postprandial power reduction and this was not considered to indicate an abnormality in the absence of a significant dysrhythmia. Figure 1 shows an example of a pseudo three dimensional representation of an analysed EGG in an asymptomatic control subject. The electrical activity was stable and did not change significantly after a standard test meal.

An abnormal EGG was present in two (7\%) asymptomatic controls, two (10\%) GORD patients with acid reflux, and $10(50 \%)$ GORD patients with food regurgitation. GORD patients with food regurgitation, but not solely acid reflux, were significantly more likely to have an abnormal EGG compared with asymptomatic controls $(p<0.001)$. Figure 2 shows an example of a pseudo three dimensional representation of an EGG in a patient with food regurgitation, demonstrating abnormal pacemaker activity throughout the recording.

EGG parameters were analysed individually (table 1). GORD patients with only acid reflux did not differ significantly in any EGG parameter compared with controls. In contrast, GORD patients with food regurgitation had significantly more tachygastrias both before $(\mathrm{p}<0.02)$ and after $(\mathrm{p}<0.01)$ the test meal. Regurgitation patients also had a more unstable electrical frequency (calculated as the dominant frequency instability coefficient) following the test meal $(\mathrm{p}<0.003)$.

Oesophageal manometry and 24 hour $\mathrm{pH}$ data were available for analysis in all GORD patients with acid reflux and in 13/20 with food regurgitation (table 2). Oesophageal motility disorders were found in four patients with acid reflux (three non-specific, one sclerodermalike oesophagus), and two regurgitation patients (two non-specific). GORD patients with food regurgitation and an abnormal EGG had higher oesophageal acid exposure than those with a normal EGG $(p<0.05)$. When food regurgitators with normal and abnormal EGG were compared, no difference in any lower oesophageal sphincter measurement was observed. However, a 1:1 association between severity of oesophageal acid exposure and an abnormal EGG was not apparent, as some patients with severe GORD had a normal EGG.

\section{Results}

Mean ages in the patient groups were: controls 27 years; acid reflux 42 years; and food regurgitation 52 years. Female/male ratios were: controls 17/13; acid reflux 14/6; and food regur-

\section{Discussion}

This study has documented the prevalence of EGG abnormalities in GORD. Abnormality of 
the EGG depends on the nature of the refluxate material. Half of the GORD patients complaining of food regurgitation had an abnormal EGG while in those with solely acid reflux there was no difference in gastric pacemaker activity compared with asymptomatic controls. Regurgitation patients had significantly more tachygastrias both before and after a test meal. Tachygastrias have been shown to correlate with antral hypomotility. ${ }^{12}$ The findings suggest that half of patients with food regurgitation have associated antral hypomotility. Half of patients with food regurgitation had a normal EGG. The reason for this is unclear but may reflect either a different pathogenesis or that in these patients gastric dysrhythmias are transient and were not detected at the time of testing.

GORD patients with food regurgitation and an abnormal EGG had significantly greater oesophageal acid exposure than those with a normal EGG. There was no significant difference in the lower oesophageal sphincter between food regurgitators with normal and abnormal EGG suggesting that gastric dysrhythmias add to the degree of acid reflux. However, a large amount of oesophageal acid exposure was not always associated with an abnormal EGG, supporting the concept of a multifactorial pathogenesis for GORD.

The observation that gastric pacemaker activity may be abnormal in food regurgitation suggests that an antroduodenal motility disorder might be a confounding factor in these patients. Antroduodenal manometry is invasive and an abnormal EGG may act as a screening test to define patients where further testing is justified. This requires further study.

This study excluded patients with Barrett's oesophagus and benign oesophageal strictures. These subgroups deserve further study. Antropyloroduodenal incoordination when combined with gastro-oesophageal reflux may cause regurgitation of bile into the oesophagus. ${ }^{10}$ This is a suggested pathogenic mechanism in Barrett's oesophagus. ${ }^{24}$ The EGG may therefore shed further light on the pathogenesis of complicated GORD.

Identification of EGG abnormalities in GORD patients may also have implications for treatment. The prokinetic agents cisapride and domperidone have been reported to improve EGG abnormalities in functional dyspepsia and gastroparesis. ${ }^{25-28}$ These types of agents may have a particularly useful role in GORD patients with food regurgitation.

1 Abell TL, Malagelada JR. Glucagon-evoked gastric dysrhythmias in humans shown by an improved electrogastrographic technique. Gastroenterology 1985;88:1932-40.
2 You CH, Chey WY. Study of electromechanical activity of the stomach in humans and dogs with particular attention to tachygastria. Gastroenterology 1984;86:1460-8.

3 van der Schee EJ, Grashuis JL. Contraction related, low-frequency components in canine electrogastrographic signals. Am f Physiol 1983;245:G470-5.

4 Chen J, Richards RD, McCallum RW. The cutaneous electrogastrogram reveals important information about gastric motility. Gastroenterology 1990;99:A1208.

5 Smout AJPM, van der Schee EJ, Grashuis JL. What is measured in electrogastrography? Dig Dis Sci 1980;25:17987.

6 Hamilton JW, Bellahsene BE, Reichelderfer M, et al. Human electrogastrograms. Comparison of surface and mucosal recordings. Dig Dis Sci 1986;31:33-9.

7 Mintchev MP, Kingma YJ, Bowes KL. Accuracy of cutaneous recordings of gastric electrical activity. Gastroenterology 1993;104:1273-80.

8 Riezzo G, Pezzolla F, Thouvenot J, et al. Reproducibility of cutaneous electrogastrography in the fasting state in man. Pathol Biol 1992;40:889-94.

9 Parkman HP, Harris AD, Miller MA, et al. Influence of age, gender and menstrual cycle on the normal electrogastrogram. Am $\mathcal{f}$ Gastro 1996;91:127-33.

10 Parkman HP, Fisher RS. Contributing role of motility abnormalities in the pathogenesis of gastroesophageal reflux disease. Dig Dis 1997;15(suppl 1):40-52.

11 McCallum RW. Gastric emptying in gastroesophageal reflux and the therapeutic role of prokinetic agents. Gastroenterol Clin North Am 1990;19:551-64.

12 Chen JDZ, Lin Z, Pan J, et al. Abnormal gastric myoelectrical activity and delayed gastric emptying in patients with symptoms suggestive of gastroparesis. Dig Dis Sci 1996;41: 1538-45.

13 Leahy A, Besherdas K, Clayman C, et al. Abnormalities of the electrogastrogram in functional gastrointestinal disorders. Am $\mathcal{7}$ Gastroenterol 1999;94:1023-8.

14 Abell TL, Camilleri M, Hench VS, et al. Gastric electromechanical function and gastric empting in diabetic gastroparesis. Eur f Gastroenterol Hepatol 1991;3:163-7.

15 Rothstein RD, Alavi A, Reynolds JC. Electrogastrography in patients with gastroparesis and effect of long term cisapride. Dig Dis Sci 1993;38:1518-24

16 Stern RM, Koch KL, Stewart WR, et al. Spectral analysis of tachygastria recorded during motion sickness. Gastroenterology 1987;92:92-7.

17 Koch KL, Stern RM, Vasey M, et al. Gastric dysrhythmias and nausea of pregnancy. Dig Dis Sci 1990;35:961-8.

18 Abell TL, Malagelada J-R, Lucas AR, et al. Gastric electromechanical and neurohormonal function in anorexia nervosa. Gastroenterology 1987;93:958-65.

19 Orr WC, Zhang M, McClanahan J, et al. Impaired gastric myoelectrical activity in elderly patients with GERD. Gastroenterology 1997;112:A896.

20 Camilleri M, Hasler WL, Parkman, et al. Measurement of gastrointestinal motility in the GI laboratory. Gastroenterology 1998; 115:747-62.

21 Levanon D, Chen JZ. Electrogastrography: its role in managing gastric disorders. F Pediatr Gastroenterol Nutr 1998; 27:431-43.

22 Johnson LF, Demeester TR. Development of the 24 hour intraesophageal $\mathrm{pH}$ monitoring composite scoring system. f Clin Gastroenterol 1986;8(suppl 1):52-8.

23 Chen J, McCallum RW. Gastric slow wave abnormalities in patients with gastroparesis. Am f Gastroenterology 1992;87: $477-82$.

24 Vaezi MF, Singh S, Richter JE. Role of acid and duodenogastric reflux in esophageal mucosal injury: a review of animal and human studies. Gastroenterology 1995; 108:1897-907.

25 Riezzo G, Cucchiara S, Chiloiro M, et al. Gastric emptying and myoelectrical activity in children with non-ulcer dyspepsia. Effect of cisapride. Dig Dis Sci 1995;40:142834.

26 Besherdas K, Leahy A, Mason I, et al. The effect of cisapride on dyspepsia symptoms and the electrogastrogram in patients with non-ulcer dyspepsia. Aliment Pharmacol Ther 1998;12:755-9

27 Rothstein RD, Alavi A, Reynolds JC. Electrogastrography in patients with gastroparesis and effect of long term cisapride. Dig Dis Sci 1993;38:1518-24.

28 Koch KL, Stern RM, Stewart WR, et al. Gastric emptying and gastric myoelectrical activity in patients with diabetic gastroparesis: Effect of long term domperidone treatment. Am $\mathcal{F}$ Gastroenterol 1989;84:1069-75. 